\title{
Escape-capture bigeminy caused by blocked atrial extrasystoles
}

\author{
A. Dubb and L. Schamroth \\ From the Baragwanath Hospital and the University of the Witwatersrand, Fohannesburg, S.A.
}

A further mechanism of escape-capture bigeminy is described, viz. blocked atrial extrasystoles.

Escape-capture bigeminy was so called by Bradley and Marriott (1958), and refers to a bigeminal rhythm which is caused by an escape beat followed by a conducted beat. Three basic mechanisms have been described (Schamroth and Dubb, 1965).

I) A basic 3:I sinoatrial block; the blocked impulses allowing an atrioventricular nodal (or ventricular) escape beat which occurs coincidentally with, and is dissociated from, the first sinus beat of the next ensuing 3:I sequence.

2) A basic 3:2 atrioventricular block; the blocked impulse allowing an atrioventricular nodal (or ventricular) escape beat which is coincident with, and dissociated from, the next sinus impulse - the first of the ensuing 3:2 atrioventricular sequence.

3) A potential 3:2 atrioventricular block of the Wenckebach type ending in a reciprocal return of the atrial impulse to the atria (reversed reciprocal rhythm) - an atrial echo - which discharges the sinus pacemaker and thereby allows an atrioventricular nodal escape beat, which is coincident with, and dissociated from, the next potential sinus beat.

We present a hitherto unrecognized fourth mechanism caused by blocked atrial extrasystoles.

\section{Case report}

The electrocardiogram (Fig.) was recorded from a 50year-old woman receiving digitalis for a congestive cardiomyopathy. The tracing shows a basic sinus rhythm of 94 per minute $(P P$ interval $=0.64 \mathrm{~s})$. The first sinus $\mathbf{P}$ wave of the tracing precedes but is dissociated from the QRS complex of the atrioventricular nodal escape beat. This is followed by a conducted sinus beat (PR interval $=0.17 \mathrm{~s}$ ). This in turn is followed by a nonconducted atrial extrasystole whose $\mathbf{P}^{\prime}$ wave is superimposed upon, and deforms, the ST segment of the conducted sinus beat. This leads to a further atrioventricular nodal escape dissociated from the ensuing sinus beat. The blocked atrial extrasystole occurs after every second sinus $P$ wave and this results in an escapecapture bigeminy.

\section{Discussion}

The blocked atrial extrasystole discharges the sinoatrial node and is blocked at the atrioventricular node. The next sinus $\mathbf{P}$ wave occurs after an interval which is slightly longer than the sinus PP interval. Thus the P'P interval measures $0.75 \mathrm{~s}$. This is caused by temporary depression of the sinoatrial node resulting from its premature discharge (Pick, Langendorf, and Katz, I95I). The effective sinus cycle, i.e. the sinus cycle which is effective or relevant to the atrioventricular nodal pacemaker (Schamroth and Dubb, 1965) is the PP interval encompassing the blocked atrial extrasystole, i.e. the sum of preand post-extrasystolic $P P$ intervals; $\mathbf{P P}^{\prime}+\mathbf{P}^{\prime} \mathbf{P}$ which equals I.I2s. This is slightly longer than the atrioventricular nodal escape rhythm and thereby permits the escape of the atrioventricular nodal pacemaker - the escape interval being $1.00 \mathrm{~s}$.

The escape beat has an obviously inverted $T$

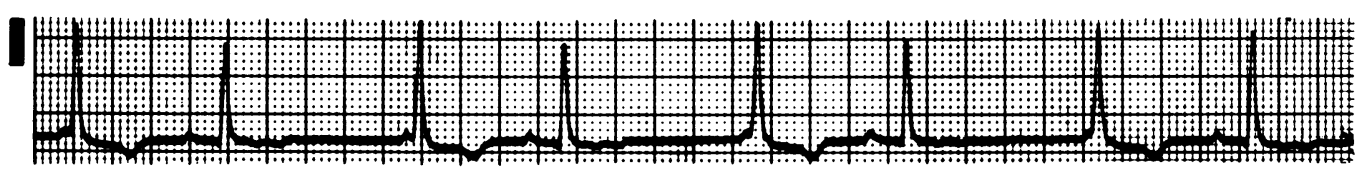

FIG. Electrocardiogram (standard lead I), showing escape-capture bigeminy. 
wave whereas the $T$ wave of the conducted sinus beat is equiphasic. This is an expression of socalled 'post-extrasystolic' $T$ wave change and is caused by the long pause which the blocked atrial extrasystole occasions. The manifestation usually connotes organic heart disease (Mann and Burchell, 1954).

\section{References}

Bradley, S. M., and Marriott, H. J. L. (1958). Escape-capture bigeminy. Report of a case of A-V dissociation initiated by $2: 1$ S-A block with resulting bigeminal rhythm. American Fournal of Cardiology, 1, 640 .
Mann, R. H., and Burchell, H. B. (1954). Significance of Twave inversion in sinus beats following ventricular extrasystoles. American Heart fournal, 47, 504.

Pick, A., Langendorf, R., and Katz, L. N. (195I). Depression of cardiac pacemakers by premature impulses. American Heart fournal, 4r, 49.

Schamroth, L., and Dubb, A. (1965). Escape-capture bigeminy. Mechanisms in S-A block, A-V block and reversed reciprocal rhythm. British Heart fournal, 27, 667.

Requests for reprints to Dr. A. Dubb, Department of Medicine, Baragwanath Hospital, P.O. Bertsham, Johannesburg, South Africa. 